\title{
ЛЕГЕНДА О МАРКЕ ФУРИИ КАМИЛЛЕ В АНТИЧНОЙ ТРАДИЦИИ: ЗАБЫТЫЙ ОБЕТ АПОЛЛОНУ
}

\section{TO THE LEGEND OF CAMILLUS: THE FORGOTTEN VOW TO APOLLO}

I. Stepanov

Summary: This article discusses the legend of Marcus Furius Camillus on the example of an episode with the vow to Apollo. It is assumed that there is some initial version of the legend, the closest to which Plutarch is located. He does not give the heroic character of the appearance of Camillus and presents the episode as simply as possible. Titus Livius changed this option, presenting Camillus as a model of piety. Appian, on the other hand, developed a version of Plutarch and obtained an impious character with a pragmatic view of religion.

Keywords: historiography, legend, Camillus, Livy, Appian, Plutarch.

\author{
Степанов Игорь Николаевич \\ Аспирант, Санкт-Петербургский государственный \\ университет, г. Санкт-Петербург \\ st081013@student.spbu.ru
}

Аннотация: В данной статье рассматривается предание о Марке Фурии Камилле на примере эпизода с данным им обетом Аполлону. Делается предположение о наличии некоего первоначального варианта легенды, ближе всего к которому находится Плутарх. Он не придает героического характера облику Камилла и излагает эпизод максимально просто. Тит Ливий изменил этот вариант, представив Камилла как образец благочестия. Аппиан же развил версию Плутарха и получил неблагочестивого персонажа с прагматическими взглядами на религию.

Ключевые слова: историография, легенда, Камилл, Ливий, Аппиан, Плутарх.
$\mathrm{O}$ бет богам - важная часть общественной жизни Рима, поскольку в этом действии «ярко проявлялось сплочение богов и людей» [1, с. 289]. У античных авторов можно найти множество мест, в которых они пишут о важности этой процедуры для римской общины (Cic. Leg. II. 22, 41). Ввиду этого можно сказать, что при наличии сообщения об обете, данном некой выдающейся личностью, древний историк не мог не обратить на него внимания, но должен был осмыслить и включить в свое повествование. Это наглядно видно на примере биографии Марка Фурия Камилла, знаменитого деятеля времен ранней Республики, «второго основателя Рима», спасшего его от галлов. Тит Ливий, Плутарх и Аппиан упоминают об одном из важнейших религиозных деяний героя - обетовании десятой части добычи Аполлону, совершенном Камиллом перед штурмом Вей, этрусского города, соперника Рима в могуществе, осада которого римлянами длилась десять лет. Обет этот ввиду больших обязательств, которые возложил Камилл на общину (десятая часть вейской добычи), представляет пример конфликта материальных и религиозных интересов, от его разрешения зависела дальнейшая жизнь общины. И именно на примере этого эпизода можно увидеть, сколь сильно влияло мировоззрение автора на его повествование.

В историографии этот эпизод и его интерпретация древними авторами освещены недостаточно. Зачастую этот обет просто упоминается исследователем, который не подвергает его должному анализу. Ярким примером этого является статья В.Н. Токмакова, посвященная образу Камилла, где он просто упоминает этот обет в одном предложении: «к публичным добавились и частные обеты посвятить Аполлону десятую часть всей добычи» [3, с. 589]. Очень странное заявление, учитывая, что выполнение обета легло на население Рима. Эмануэль Ханнак, делая в своем труде достаточно широкие обобщения, в случае с данным эпизодом у Аппиана ограничивается простой передачей его содержания и констатацией отличий от версии Ливия и Плутарха [5, S. 71].

Наиболее полно обет Камилла Аполлону в труде Ливия исследован Дэвидом Левином. При рассмотрении данного эпизода исследователь, конечно, привлекает материал Аппиана и Плутарха, но, поскольку это не входило в его задачи, не проводит тщательный анализ их трактовок. Они нужны лишь для того, чтобы показать своеобразие Ливия, который, по мысли исследователя, противопоставляет, если можно так выразиться, почти абсолютное благочестие Камилла и благочестие обычного человека, которым отличалось тогда население Рима [9, р. 189-190].

А.М. Сморчков также обстоятельно рассматривает обет Камилла в изложении Ливия с точки зрения процедуры принятия и исполнения. Он указывает, что при его исполнении с религиозными столкнулись материальные интересы, поскольку Камилл обязал к исполнению этого обета римское общество в целом [2, с. 116].

Эпизод с обетом Камилла у Ливия имеет долгую предысторию, которая начинается с пророчества об Альбанском озере. Его наш автор передает в двух местах: в одном он говорит о словах пророческих книг по этому 
поводу (Liv. V, 15, 11), в другом приводит ответ дельфийского оракула (Liv. V, 16, 9): «Римлянин! Остерегись воду альбанскую в озере держать, остерегись и в море ее спускать. Да растечется она по полям, да оросит их, да исчерпается, по рекам разлившись. [...] По свершении рати пусть победитель принесет в мой храм богатые дары и восстановит обычайные отеческие священнодейства, что ныне небрежны» (пер. С.А. Иванова)'. В вариантах этого оракула, приведенных Плутархом (Cam. 4) и Дионисием (Rom. Ant. XII, 11, 2), римляне называются врагами, у Ливия же приводится некий Romanus. Это интересно по двум причинам: во-первых, божество не воспринимает римлян в качестве врагов, но подсказывает им пути к победе. Во-вторых, почему употреблено единственное число? Вполне вероятно, потому, что Romanus олицетворяет собой весь римский народ. Т.е. использование этого слова вполне оправдывается синекдохой [13, р. 662]. Но, быть может, Romanus предполагает пришествие некоего героя, спасителя, если можно так выразиться? И этим героем является Камилл, включенный в повествование как раз после исполнения условий оракула, поскольку в дальнейшем Ливий определяет Камилла как dux fatalis, т.е. «судьбоносный вождь» (Liv. V, 19, 2). Об этом свидетельствует и молитва Камилла Аполлону Пифийскому во время штурма Вей: «Под твоим водительством [...], о Пифийский Аполлон, и побужденный твоей силой выступаю я для ниспровержения града Вейи и тебе посвящаю десятую часть добычи»².

Камилл у Ливия говорит, что он выступает instinctus numine («побужденный божественной силой»). Глагол instinguo означает сподвигать, побуждать кого-нибудь к чему-нибудь. В качестве «побудителей» у Ливия равно встречаются боги (Liv. V, 15, 10), люди (Liv. I, 47, 7) и их чувства (Liv. VI, 33, 2). В нашем случае побуждающий момент - божественная сила Аполлона. При этом стоит отметить, что Аполлон не только сподвигает Камилла на деяние, но и направляет его, как об этом говорит сам герой: «tuo ductu [...], Pythice Apollo». При этом Камилл, давая обет, следует указаниям Дельфийского оракула, который потребовал богатые дары после победы. Представляется, что Камилл в данной молитве умаляет свою личность, свою волю, полностью подчиняя их своему божественному покровителю, как раз эта мысль выражается в определении dux fatalis. В этой молитве Ливий провел явную связь между Аполлоном и Камиллом. Мне кажется, что связь эта в большей степени личная, чем может показаться, поскольку представляется, что Ка- милл, вероятнее всего, дал этот обет в одиночестве. Чтобы понять эту связь, стоит обратиться к общей практике обета. Йорг Рюпке пишет, что обеты, данные полководцем перед битвой, как правило, преследовали цель ободрить войско, поэтому он стремился сделать известным своим воинам содержание обета [15, S. 155], но, как станет ясно из последующего повествования, подчиненные нашего героя узнали о нем только после того, как они эту добычу уже получили, и Камилл провел свой триумф. А.М. Сморчков пишет, что и понтифики не принимали участия в обете, допуская при этом, что они могли присутствовать [1, с. 329]. Это допущение кажется лишним. Когда Ливий пишет следующие строки: «Затем идет дело о даре Аполлону. Когда Камилл сказал, что обетовал ему десятую часть добычи, понтифики решили [...]»³, то подразумевает, что понтифики узнали об обете позже со слов Камилла.

Поскольку все узнали об этом обете только после раздела добычи, то власть оказалась в затруднительном положении. Каким образом взыскать с нее десятую часть? Поскольку собрать добычу обратно не представлялось возможным, то понтифики решили освободить народ от обета. Камилл воспротивился этому, в результате переговоров договорились о том, что каждый сам оценит добычу и отдаст десятую часть государству (Liv. V, 13, 8-11). Казалось, что вопрос с обетом исчерпан, плебеи вернулись к делам земным и вновь вспомнили о своем бедственном положении, когда было выдвинуто требование о переселении в Вейи. Представляется, что это требование - олицетворение всех материальных, земных, низких дел. Как раз во время спора по вопросу переселения в повествовании вновь появляется Камилл как противоположность материальному. Ливий (V, $25,4-6)$ пишет, что Камилл «всюду публично выступал с такими речами: неудивительно, что государство сошло с ума, если оно, будучи связано обетом, считает любую заботу важнее заботы об исполнении религиозного долга. [...] Но ему, Камиллу, совесть не позволяет умолчать, что десятина назначается только из добычи в виде движимого имущества» (пер. С.А. Иванова). Камилл требовал признать включенной в обет и завоеванную землю. При этом вопрос показался сенату спорным, ввиду чего он был вынужден обратиться к понтификам, которые, обсудив его с Камиллом, решили, что в обет была включена десятина от всей добычи, включая землю (Liv. V, 25, 7). Особо отмечу, что даже сенат был в сомнении, понимая, что требование Камилла еще более усугубит положение

1 Romane, aquam Albanam cave lacu contineri, cave in mare manare suo flumine sinas; emissam per agros rigabis dissipatamque rivis exstingues; [...] bello perfecto donum amplum victor ad mea templa portato, sacraque patria, quorum omissa cura est, instaurata ut adsolet facito» (Liv. V, 16, 9).

2 tuo ductu [...], Pythice Apollo, tuoque numine instinctus pergo ad delendam urbem Veios tibique hinc decimam partem praedae voveo (Liv. V, 21, 2).

3 agi deinde de Apollinis dono coeptum. cui se decimam vovisse praedae partem cum diceret Camillus, pontifices [...] censerent (Liv. V, $23,8)$ 
народа и государства, т.е. его могли поколебать материальные соображения. Камилл же в изображении Ливия по своему благочестию и по уровню своих познаний в делах религии приближается к жрецам. Его поступки прежде всего определяются правилами религии.

Из вышесказанного можно заключить, что данный эпизод у Ливия носит строго продуманный характер (знамение, обусловившее обет, - сам обет - исполнение обета), он является неотъемлемой частью образа Камилла. Соответственно, Камилл присутствует в божественном замысле, он исполняет высшую волю. Исполнение ее может входить в противоречие с материальными интересами, которые олицетворяются требованием переселения в Вейи, но должно преодолеть их. Фактически суть эпизода выражается определением Камилла у Ливия - dux fatalis.

Теперь обратимся к Плутарху. У херонейского историка нет прямой связи между посольством в Дельфы по поводу знамения об Альбанском озере и обетом Камилла Аполлону, он впервые упоминает о последнем только при описании ненависти, которую вызвал наш герой у народа. Плутарх (Cam. 7) передает, что главным поводом этой вражды стало недоразумение с обетом Аполлону: «[...] когда Вейи были взяты и разграблены, он, то ли не решившись докучать согражданам, то ли под бременем повседневных забот просто запамятовав о своем обете, оставил все богатства у их новых владельцев. Впоследствии, однако, когда срок его полномочий уже истек, он донес об этом случае сенату, и в то же время жрецы объявили, что жертвы возвещают гнев богов, требующий умилостивительных и благодарственных обрядов» (пер. С.П. Маркиша). У Ливия Камилл фактически живет религией, но Плутарх (Cam. 8) предполагает, что римский политический деятель времен Ранней Республики, образец доблести, при столкновении с противоречием между исполнением религиозного долга и материальными интересами мог растеряться: «Камилл, не зная, что ответить на их упреки и не находя лучшего оправдания, прибег к самому нелепому, признавшись, что забыл об обете» (пер. С.П. Маркиша). Хотя очевидно, что он, по мнению Плутарха, помнил об обете, о чем свидетельствуют сами слова Плутарха и тот факт, что свой обет Юноне он помнил хорошо (Plut. Cam. 6). Если у Ливия Камилл в своем благочестии возвышается над благочестием окружения, то Плутарх наделяет Камилла «обычным» благочестием. Религия для него второстепенна. Дав обет, он не подумал, каким образом его исполнить, ибо херонейский историк показывает растерянность Камилла.

Кажется, что Плутарх заимствовал этот эпизод у своего источника, возможно, у Дионисия Галикарнасского [5, S. 22], а возможно, его предшественника [8, S. 282-285], поскольку он не связан прочно с повествованием, он не привносит в образ Камилла никаких дополнительных характеристик. Плутарх, вероятно, упомянул его с чисто антикварным интересом. Но почему именно эту версию? Почему не версию Ливия, с произведением которого он был знаком (Plut. Cam. 6)? Кажется, ответ кроется в мировоззрении писателя, в его любви к людям. Камилл у Ливия недосягаем в благочестии своем, Плутарх же очеловечивает его, показывает сложный моральный выбор, вставший перед ним: исполнить долг перед богами или войти в положение бедствующего народа. Ведь Камилл у Плутарха глубоко человечен, историк пишет, что Камилл обладал кротким и мягким характером (Plut. Cam. 11).

Перейдем к «Римской истории» Аппиана Александрийского. К сожалению, от интересующих книг сохранились лишь отрывки, иногда весьма обширные, что дает возможность их исследования и характеристики. В первую очередь для темы интересен отрывок, в котором Аппиан, в общем повторяя мысль Плутарха, говорит об обете Камилла Аполлону (App. Ital. VIII. 1):

1. После завершения вейских дел от Зевса пришли неблагоприятные знамения, которые были истолкованы прорицателями в том смысле, что было упущено нечто относящееся к благочестию.

2. Камилл сообщает сенату, что забыл посвятить

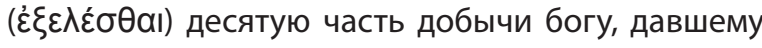
предсказание об озере.

3. Сенат приказывает самостоятельно определить десятину, причем под влиянием богобоязненно-

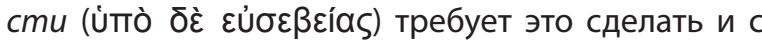
проданной землей.

У Ливия и Плутарха Камилл сам вспоминает об обете, его к этому толкает сознание невыполненного долга. У Аппиана же наш герой забыл дать его! И вспоминает о своей ошибке только после появления свидетельств божественного гнева. При этом, если Плутарх использует

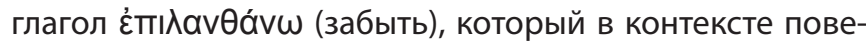
ствования Плутарха свидетельствует о некоторой рас-

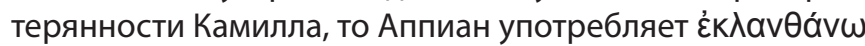
(забыть совершенно). Если к этому прибавить, что Аппиан использовал материал Плутарха, и учесть замечание Генриха Ниссена о «болезненной» склонности Аппиана, не сообразуясь с текстом источника, умалять одни детали и сосредотачивать пристальное внимание на других [12, S. 116], то может показаться, что наш автор усиливает картину забывчивости Камилла у Плутарха, гиперболизируя ее. Об этом свидетельствует сама суть эпизода. Аппиан акцентировал внимание на том, что Камилл совершенно забыл дать обет, поскольку герой вспомнил о нем лишь после неблагоприятных знамений. Камилл Аппиана не растерян, он не оправдывается перед народом, как Камилл Плутарха. В связи с этим обращает на себя внимание и тот факт, что «богобоязненным» называется сенат, а не наш герой, именно сенат прилагает все усилия, чтобы смягчить гнев богов. Камилл, как следует из этой части, совершенно не заботится о божественном. 
Вторая глава отрывка содержит рассказ об изгнании Камилла. Сообщения о нем встречаются и у других авторов. Суть их такова: спустя некоторое время после взятия Вей народные трибуны, возмущенные деятельностью Камилла, которая ухудшает материальное положение плебеев, выдвигают против Камилла обвинение, налагают штраф, из-за чего он добровольно отправляется в изгнание в Ардею (Plut. Cam. 11-13; Liv. V, 32, 8-9). У Плутарха и Ливия изгнание Камилла и обет Аполлону никак не связаны, но у Аппиана изгнание является прямым следствием эпизода с обетом Аполлону, поскольку причиной обвинения Камилла являются неблагоприятные знамения, полученные по его вине.

Эмануэль Ханнак пишет, что обвинение базируется у Аппиана на нелепом основании [5, S. 71]. Мне же представляется обратное - у Ливия и Плутарха обвинение выглядит нелепым, поскольку и сами авторы, и читатель понимают, что оно ложное. Но у Аппиана сюжет построен совершенно иначе. Именно Камилл забыл об обете, причем забыл так крепко, что только боги смогли пробудить его память, в то время как у других авторов он вспомнил о нем сам. Камилл не дал обет перед взятием Вей, в качестве магистрата он не исполнил свои обязанности перед богами и людьми. Ведь слова «забыл посвятить десятую часть добычи богу, давшему предсказание относительно озера» (Арp. It. VIII, 1) (пер. С.П. Кондратьева) подразумевают, что в оракуле, данном в Дельфах, содержалось требование о богатых дарах (как у Liv. V, 16, 9). Поэтому обвинение представляется более чем оправданным. К этому можно добавить, что трудно придумать более удачный повод к обвинению, чем основанный на религии, когда обвиняемый сам вложил в руки своих врагов оружие против себя.

Любопытно, что мотив неблагочестия Камилла в этом эпизоде не был оставлен Аппианом в дальнейшем повествовании. Согласно преданию, Камилл, уходя в изгнание, обращается богам с просьбой сделать так, чтобы римляне, одолеваемые бедствиями, вынуждены были обратиться к нему за помощью. При этом Плутарх и Аппиан называют эту молитву ахиллесовой (Plut. Cam. 13; App. Celt. V). Когда эта молитва исполняется после нашествия галлов, и сограждане действительно обращаются к Камиллу за помощью, он, возглавляя войско для освобождения Города произносит небольшую речь, которая при сравнении ее вариантов очень показательна для данной темы.

К примеру, у Дионисия Камилл благодарит богов за почести, под чем понимает, конечно, то, что римляне ввиду галльского нашествия вынуждены были обратиться к нему, и говорит, что более желал бы прожить в безвестности вдали от родины, чем видеть ее в таком бедствии (D.H. Rom. Antiq. XIII, 7, 3-5). Т.е. если бы бедствия были меньшего масштаба, то он не раскаялся бы в своей молитве, иначе говоря, это оценка, зависящая от внешних событий, а молитва сама по себе была справедливой.

У Аппиана Камилл выражает подобную же мысль о своем раскаянии, но при этом все же сравнивает две молитвы. Это совершенно меняет дело: «теперь молюсь бо-

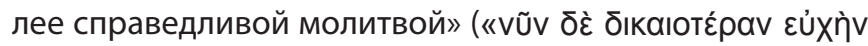

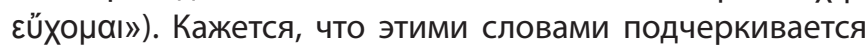
сомнительный характер старой молитвы, если учесть, что изгнание не является несправедливым. Камилл у Аппиана, вероятно, сознает свою вину, ибо выстраивается четкая последовательность: забытый обет - неблагоприятные знамения - исполнение обета сенатом - изгнание. У Аппиана Камилл, как и у Плутарха, в плане религии является обычным человеком, но Аппиан усилил этот эпизод, заставив Камилла забыть о необходимости дать обет и добавив продолжение к эпизоду с ним, которого не было у Плутарха и Ливия. Аппиан добавил расплату за неисполнение договора между богами и людьми.

Подведем итоги. Если использовать общее место в литературе, согласно которому условно менее героическая и более «простая» версия воспринимается как более древняя [6, S. 126], то таковой можно считать версию Плутарха. Херонейский историк в силу особенности метода своей работы [7, р. 86-87] излагает этот эпизод максимально просто, можно сказать, что он его упоминает, поскольку для дальнейшего повествования он не имеет никакого значения.

Предание Ливия гораздо сложнее, оно явно носит следы переработки, оно полностью вписывается в концепцию римского историка о почти абсолютном благочестии Камилла. Ливий не мог допустить, чтобы образец доблести, пример современному ему веку, оказался неблагочестив. Вероятно, выполненное с таким мастерством включение эпизода в повествование является ответом на общую версию о забытом обете, которую Ливий нашел в своем источнике. Выстраивая схему «знамение об Альбанском озере - обет - исполнение обета», римский историк доказывает читателю благочестие Камилла. Но доказывает в не совсем привычном для нас смысле. Он обосновывает свой взгляд правдоподобием. Как пишет Т. Д. Люс, Ливий использовал применительно к ранней истории Рима метод художественной реконструкции [10, р. 186]. Он восстанавливал события в соответствии с духом, который, как ему казалось, он уловил.

Аппиан же, выстраивая линию «забытый обет - неблагоприятные знамения - исполнение обета сенатом - изгнание», усиливает почерпнутую у Плутарха версию забытого обета. Камилла постигло возмездие за забытый обет, его более благочестивые сограждане наказали его. Вероятно, Аппиан попытался устранить некоторые несоответствия, которые он находит в своих источниках, ведь обвинение у Ливия и Плутарха выглядит надуманным. 
При этом может показаться, что Плутарх был в одном шаге от интерпретации Аппиана, у него есть забытый обет, есть неблагоприятные знамения, он сомневается в обвинении (Plut. Cam. 12). Кажется, что у него нет только связи этих элементов. Эту связь проводит Аппиан. В результате у Аппиана Камилл предстает, если можно так выразиться, обычной выдающейся личностью. Не героем, а лишь одним из сотен себе подобных. Он отличается доблестью, умом, но в то же время не лишен человеческих недостатков. К религии относится совершенно спокойно, его вера не выходит за рамки веры обычного человека, он не готов ради нее жертвовать всем, более того, наш герой может поступиться ею без особенных угрызений совести.

Таким образом, на примере небольшого эпизода можно наглядно проследить влияние мировоззрения автора на трактовку предания. Другими словами, искать объяснение необходимо прежде всего во взглядах автора и во внутренней логике текста, а уж потом - в возможном источнике.

\section{ЛИТЕРАТУРА}

1. Сморчков А.М. Религия и власть в Римской республике: магистраты, жрецы, храмы. М.: Изд-во РГГУ, 2012.602 с.

2. Сморчков А.М. Храмовый обет (votum) в религиозно-политической практике республиканского Рима // Античный мир и археология. Вып. 14. Саратов, 2010. C. 107-121.

3. Токмаков В.Н. Марк Фурий Камилл: превратности судьбы и образа «второго Ромула» // История через личность: Историческая биография сегодня / Под ред. Л.П. Репиной. 2-е изд. М.: Квадрига, 2010. С. 582-606.

4. Appiani Historia Romana. Vol. 1: Prooemium, Iberica, Annibaica, Libyca, Illyrica, Mithridatica, Fragmenta / Ed. P. Viereck, A.G. Roos, E. Gabba. Lipsiae: In aedibus B.C. Teubneri, 1962. 545 c.

5. Hannak E. Appianus und seine Quellen. Allgemeines über Appianus und sein Werk. Die fragmentarisch überlieferten Bücher. Wien: Beck'sche UniversitätsBuchhandlung, 1910.498 c.

6. Hirschfeld 0. Zur Camillus-Legende. // Festschrift zum fünfzigjährigen Doctorjubiläum Ludwig Friedlaender. Dargebracht von seinen Schülern. Leipzig: Verlag von S. Hirzel, 1895. S. 125-138.

7. Jacobs Susan G. Plutarch's Pragmatic Biographies. Lessons for Statesmen and Generals in the Parallel Lives. Columbia Studies in the Classical Tradition. Vol. 43. Boston: Brill, 2017. $471 \mathrm{c}$.

8. Klotz A. Zu den Quellen der plutarchischen Lebensbeschreibung des Camillus. // Rheinisches Museum für Philologie, Neue Folge. 1941. 90. Bd., 4. H. S. 282-309.

9. Leven D.S. Religion in Livy. Leiden, New York, Köln: E.J. Brill, 1993. 259 c.

10. Luce T.J. Design and Structure in Livy: 5.32-55 // 0xford Readings in Classical Studies. Livy. Ed. Chaplin J.D., Kraus C.S. New York: Oxford University Press, 2009. P. 148-191.

11. Livius T. Titi Livi ab urbe condita libri editionem priman curavit Guilelmus Weissenborn editio altera auam curavit Mauritius Mueller Pars I. Libri I-X. Editio Stereotypica. Leipzig: Teubner, 1898. 398 c.

12. Nissen H. Kritische Untersuchungen über die Quellen der vierten und fünften Dekade des Livius. Berlin: Weidmannsche Buchhandlung, 1863. 342 c.

13. Ogilvie R.M. A commentary on Livy, books 1-5. Oxford: Oxford University Press, 1965. 777 c.

14. Plutarch. Plutarch's Lives with an English Translation by Bernadotte Perrin. In eleven volumes. Vol. II, IX. London: William Heinemann Ltd., 1959. 631, 620 c.

15. Rüpke J. Domi militiae. Die religiöse Konstruktion des Krieges in Rom. Stuttgart: Franz Steiner Verlag, 1990. 305 c. 